\title{
The Teaching Method of Creative Education
}

\author{
Yong Gil Lee ${ }^{1,2}$ \\ ${ }^{1}$ Kunjang University College, Gunsan, Republic of Korea \\ ${ }^{2}$ Creative Education Society, Gunsan, Republic of Korea \\ Email: yglee@kunjang.ac.kr
}

Received June $18^{\text {th }}$, 2013; revised July $18^{\text {th }}$, 2013; accepted July $25^{\text {th }}$, 2013

Copyright (c) 2013 Yong Gil Lee. This is an open access article distributed under the Creative Commons Attribution License, which permits unrestricted use, distribution, and reproduction in any medium, provided the original work is properly cited.

\begin{abstract}
This paper is the study on the meaning of 5 stages of teaching in creative education. The five-stage teaching of creative education is one of the teaching methods set up as educational methodology for the education purpose of human creativity cultivation. Creativity is understood as universal and holistic aspect of human in creative education, and the spheres of creativity can be classified into physical-physiological sphere, social sphere, rational sphere, moral sphere, artistic sphere, and religious sphere in human life and the properties of value ability in each sphere are presented. Vividness in physical-physiological sphere, cooperation in social sphere, quest in rational sphere, virtue in moral sphere, beauty in artistic sphere, and belief in religious sphere are defined as the properties of value ability and presented the educational purpose. Such spheres of creativity distinguish universal human life and the cultivation of creativity are established as the educational purpose. Teaching method in creative education consists of the five stages of teaching as integrated teaching-studying to cultivate the properties of value ability in each sphere of creativity, which is the stage of idea-discovery-digging-manifestation-development to encourage learner's freedom and willingness with teacher's love and guide. Learner is the subject in the study course in the five-stage teaching and it is the teaching-studying theory to cultivate value ability through the learner's thinking and experience, connecting the ideal type of thinking for value creation to the ideal type of teaching-studying. Freedom and willingness as the ideal type of thinking for value creation are explained in theoretical level and the actual measure for education is tried in the teaching theory by the five-stage teaching of idea-discovery-digging-manifestation-development as the ideal type of teaching-studying. In other words, creative education is to build the ideal type of thinking for value creation in advance and then present the corresponding teaching-studying. The five-stage of teaching in creative education is to build theoretical system of education to allow students to make creative value by themselves through the cultivation of human ability, changing logical order to time series in thinking and then applying it to education. The five-stage of teaching in creative education is the formulization of thinking for value education applied to studying. It is theoretical composition of the stages to develop thinking for value creation through the experiences of the activity spheres, placing the study course to the learners. The five-stage of teaching can present the educational course as creative ability cultivation as well as the teaching for realization of educational self.
\end{abstract}

Keywords: Creative; Creative Education; Teaching Method; Educational Love; Educational Self; The Five-Stage Teaching; Idea; Discovery; Digging; Manifestation; Development

\section{Introduction}

Creative education in this study for the teaching method of creative education means the education to make students build up their character and create value though the cultivation of human ability. In other words, the nature of education is to develop creativity in diverse human capabilities, as the purpose of education is the cultivation of human capability comprehensively. The nature of education, therefore, is creativity and the creative education is to develop human creativity.

Thus, to realize creativity is the realization of character that is based on love. Love, is presented as educational love in creative education. The educational love is the common denominator of education whether education maintains certain position or not. Educational love can be achieved through the realization of educational self, and the educational self allows human's self activity. Human's self activity can be developed from heteronomous activity to autonomous activity and then from autonomous activity to value activity. Value activity is the activity orientated by education heteronomously, and autonomous activity is the process activity to create value activity (Lee Jong-Rok, 1996). Such process activity emerges by educational self.

Educational self is every subjective and conscious activity to be conducted educationally for the purposes of value discovery, value orientation, and value realization. Humans can pursue value activity, create personal character, and newly create society and culture through such educational self. Thus, educational self makes creativity that is inherent in human to be shown by individual originality and absoluteness. Creative value can be achieved through the activity and experience by educational self (Lee Yong-Gil, 2001). 
The theory for the teaching method of creative education is derived from the above context. Considering that the basis of creativity realization is love from the viewpoint of the realization of character, the action of love can excite interest and desire in every human area by making educational self be acted in education. Interest and desire produce idea, and the idea sets conception and hypothesis for the subject, a new thing is discovered and dug, and the elements of value are manifested and then the stage of development is built to produce value; it is the five stages in teaching such as idea-discovery-digging-manifestation-development.

For such theory for the teaching method of creative education, it is necessary to discuss the educational purpose of creative education, the educational methodology that is the ground of the teaching theory, and the meaning of the five stages of the leaching since theological foundation of the relationship between creativity and education can be found as an essential approach to understand the nature of creativity and be developed effectively from the aspect that creativity is human nature.

\section{Educational Purpose of Creative Education}

Creative education defines human nature as creativity, and the educational purpose in creative education is explained as "the development of human creativity". Creativity in the creative education is sought not from special human field but from human generality. Accordingly, creativity is the essence of personality in the sense of the whole person having diverse physical, psychological, emotional, and social properties and fundamental human nature (Lee Jong-Rok, 2001). Creativity is understood as universal and holistic aspect of human, and the spheres of creativity can be classified into physical-physiological sphere, social sphere, rational sphere, moral sphere, artistic sphere, and religious sphere in human life and the properties of value ability in each sphere are presented. In other words, the properties of value ability are vividness in physical-physiological sphere, cooperation in social sphere, quest in rational sphere, virtue in moral sphere, beauty in artistic sphere, and belief in religious sphere.

Such value abilities in the spheres are set to the purpose of education in creative education, and the five-stage teaching method is formed as the education method to allow students to cultivate human creative ability in the establishment of the objectives in the curriculum and subjects education by categorizing the educational objectives of creativity into the related curriculum in creative education.

What are the properties of value ability in the spheres of creativity to cultivate human creative ability as the educational objectives set in creative education?

The property of value ability in physical-physiological sphere of creativity can be express as vividness. Human body is totality of human spirit and constitution, and physiological health to maintain the vitality and health consists in biological process. Thus, creative health is to build up physical strength from biological process, and vividness is a generic term of the basis of creative health (Lee Jong-Rok, 2001). Vividness is the basis of physical-physiological property as the case of biological environment of creativity and creative behavior and health can be shown by vividness. Vividness shall be development by health study. Vividness has to be shown as the driving force of health by not only developing the teaching-learning method to build up physical strength through the area of physical educa- tion but also researching physiological sphere of humans to understand and use its property well.

The property of value ability in social sphere of creativity is cooperation.

Creative thinking, method, and behavioral mode are formed when creative individuals with originality build cooperative relationship with community or group and it will be expressed as social activities and acts and then culture can be formed based on them, according to creative education. In other words, humans are to build cooperative relationship to satisfy their desires and develop creativity to maintain the cooperation (Lee Jong-Rok, 2001).

Creative education seeks the grounds of the establishment of such cooperative relation from the individuals as social beings living with relationship each other. From the viewpoint of creative education, it is considered that humans lead social life by cooperation as relational being and social-cultural value are created through social life with cooperative relationship. Cooperation ability shall be developed through encouraged group study.

Group study can make students to build cooperation by relational being each other and allow them to understand that cooperation is the driving force of social development. According to creative education, original value of creativity can be acquired when cooperation is shown in cooperative and competitive relationship of social and relational beings. Thus, the development of cooperation ability to cultivate and encourage sociality should be achieved through teaching-studying of common study areas (Lee Jong-Rok, 2005).

The property of value ability in rational sphere of creativity is quest.

Quest ability can be shown by rationality and intellect, according to creative education. Quest is potential disposition that can be improved by education including training and exercise (Lee Jong-Rok, 2005). Quest is transferable thought as a function of advanced thinking. Accordingly, the degree of showing quest will be a measure to estimate the effect of education for creativity realization. So, the key subject is to set up and seek educational conditions of quest in teaching-studying.

To cultivate the property of value ability in quest is core teaching theory in creative education since the five stages of teaching, which are the basis of teaching method in creative education, is are based on imagination and thinking on the premise of quest. Creative thinking with originality can be shown by imagining a scene with rational thinking added with intellectual imagination and then producing the whole concep- tion by quest ability to select (Lee Yong-Gil, 2005).

To cultivate quest ability, therefore, teaching-studying shall be made by applying the five-stage teaching method. New idea should be given to learner and creative environmental atmosphere be built so that students can get knowledge voluntarily in wide range of areas (Lee Jong-Rok, 2005).

The property of value ability in moral sphere is virtue.

Subject of creativity in creative education is human being, and virtue is the realization of creativity in moral sphere, which can be practiced under moral judgment as human morality is the subject of character (Lee Jong-Rok, 2005).

Creative consciousness of virtue that is the origin of moral judgment is the freedom of conscience. As the nature of conscience is the whole and integrated action of moral consciousness, leading action prior to act, mental desire for judging action after act, inhibition to vice, righteous factors to invoke 
virtue are integrated. The foundation of moral life is considered as a creative activity in creative education as moral judgment determines its value by the act of conscience. Virtue ability to follow virtue or avoid vice can be shown based on such creative activity (Lee Jong-Rok, 2005). In other words, the ability to decide value of good and evil is shown by the ability to conduct virtue in moral judgment and practice. Virtue shall be encouraged through moral learning. Creative activity as a free will based on conscience can be conducted by cultivating the ability to conduct virtue and avoid vice based on moral learning.

The property of value ability in artistic sphere is beauty.

Aesthetic faculties are ability to sense the beauty of arts. Aesthetic faculties are innate elements in every human being. Such aesthetic faculties are creative ability to allow people to have artistic conception or art impulse or will that will evoke creative action to have creative mentality for art (Lee Jong-Rok, 2001). Aesthetic faculties are not limited to artistic areas. Creative value of aesthetic faculties creates diverse intellectual, moral, religious, and social values besides original value of art. Diverse values are formed in artistic creation in accordance with human emotions in addition to the beauty in it. Aesthetic faculties can create other values having the artistic meaning in many areas (Lee Jong-Rok, 2001).

Form the above content, it can be found that the properties of creativity that are suggested in creative education does not exist independently but relate each other in parallel structure of the value abilities. Thus, the properties of value ability as the educational objectives to be suggested in each sphere have the feature to be converged and integrated to the educational goal of creativity.

Aesthetic faculties shall be cultivated through creative studying. To cultivate aesthetic faculties is one of the works to build up an unified body of human life ultimately, and furthermore to enhance creative cultural value.

The property of value ability in religious sphere is belief.

Humans are the beings of dependence on something from the religious aspect. Dependence on something is to have the mind to depend on the absolute or the transcendent through belief or religion due to fear of unpredictable future by finding out their inability in human abilities

Religious dependence makes people build up the self having unlimited confidence and mental power. The self is belief and love. Human can seek creative self, build creative culture, and create value based on unlimited confidence, power, and patience. Belief and love can create the self by belief or religion and realize value creation by practicing the love to human belings (Lee Jong-Rok, 2001).

To cultivate the ability to believe and love, it needs to allow people to have belief and feel love through the belief. It will make people have altruistic love to serve and dedicate to others. Belief and love shall be encouraged through volunteer study, so the teaching-studying for loving country, people, and human race shall be achieved.

It can be found that the purpose of creative education is to cultivate of human beings from the above discussion. Creative education allows students to be the subject of value creation by the accomplishment of character through the cultivation of human capabilities. In short, creative education takes human creativity as the basis of educational purpose and sets up the development of creativity as educational purpose in the whole personality aspect by classifying the spheres of creativity into physical-physiological sphere, social sphere, rational sphere, moral sphere, artistic sphere, and religious sphere as universal activities of life and the presenting the development of value ability as educational goal.

\section{Teaching Method of Creative Education}

Teaching method of creative education is established by the five-stage teaching. The five-stage teaching has the stages of idea, discovery, digging, manifestation, and development as a teaching method for cultivating creative abilities of humans. The common premise for applying the five-stage teaching is the encouragement of learner's freedom and willingness, and the teaching mode should be preceded as the principle of teacher's love and guide. The details of the five-stage teaching are stated below.

\section{Idea}

The stage of idea is that of starting imagination and it is most fundamental stage for cultivating creativity but the stage from which creative activity is started. Imagination is personal and intuitive action that can be made from free and voluntary intuition. Personal integrity can be shown by the projection of individual desire or emotion from such imagination. Accordingly, the cultivation of creativity begins by starting the new integration of creativity by idea that is the action of imagination.

\section{Discovery}

The stage of discover is the process to accept the value presented in the stage of discovery and have desire and passion aiming at the value. The content of idea can be expressed concretely in this stage and the unity and order are to be built. In other words, the content or object to be found is materialized in this stage and creative thinking is presented externally and visibly to find the problem to be solved. The characteristic of learner is reflected in the process. The stage of discovery is the first stage of materialization creativity through which personal chacteristic can be seen in pure state as the learner's creativity approaches the nearest visible state.

\section{Digging}

The stage of digging is the process that the content acquired from discovery is changed to reasonable and systematic conception and then goal-oriented and unified conception can be achieved for the new value. The process of digging is to grasp the elements of problem or content acquired from the stage of discovery and then elaborate concrete creativity. Individuality or characteristic of learner intervenes the experience of creative work as the thinking in discovery stage leads to real activity. Accordingly, digging is the process that learner's individual creative ability can be built uniquely in this stage as external value shown in discovery is composed and elaborated.

\section{Manifestation}

The stage of manifestation is the process to complete a meaningful content by utilizing dug content and arranging it systematically. That is, the content in digging stage is elabo- rated by imagination for development state and it is presented in the process to build unity and order. Even if the stage of manifestation is not perfection but halfway preparation to reach the value 
of development, the purest phase can be shown prior to the stage of development.

\section{Development}

The stage of development is to complete a human ability by creating new value. So, it is the stage of application to practice and realize conception by using every thinking freely. However, the value cannot be accomplished by the completion in development stage. The true value of creativity is to stimulate willingness that causes new creativity again. We can see creative circulation process to present endless continuity of learner's development of creative ability by the five-stage teaching of creative education; it means unlimited educational possibility of human capability cultivation.

The content of creative education teaching can be shown in a model stated in Figure 1.

\section{Meaning of the Five-Stage Teaching of Creative Education}

The five stages in teaching of idea, discovery, digging, manifestation, and development are the core of creative education.

In general, the five concepts of the five stages in teaching of creative education are recognized as external procedures to occur in time series, and the five concepts are considered to be the means for teaching. It is clear that the five concepts of the five stages in teaching of creative education are the means for teaching in teaching-studying, but it is difficult to find that the five concepts can have a certain meaning in creative education based on such definition.
If teaching leads the formation of value in the learner's mind in teaching-studying conditions ultimately, the five concepts shall be also defined by the formation of value in the learner's mind. The five stages of teaching shall be an important division to grasp the action of value formation through educational self. Such division then needs to form learner's interest and desire into presentation and to materialize general meaning of creativity in the form applicable to education. If so, what is the action of value formation to cultivate creativity corresponding to each stage as a means of teaching?

We can define it by the concept of freedom and willingness. To define the concept of the five stages of teaching by the concept of freedom and willingness means that the concept of freedom and willingness can be defined by the presentation of learner's interest and desire. To show such five concepts by the presentation of interest and desire, defining them by freedom and willingness, is consistent intention to define totality of teaching method by one concept. Thus, the concepts shown in the five stages of teaching need to consider the principle of guide for learners to study with design and motivation and the principle of teacher's love and guide both.

Teaching stages of creative education contain external action and internal action; the former is the activities by students and teachers, and the latter is the formation of value in students' mind. Thus, the two aspects need to be respected equally to make the teaching stages of creative education be meaningful, and the relationship between the two aspects must be considered.

If one aspect is disregarded and another aspect only is emphasized, it would be difficult to cultivate creative ability as the

\begin{tabular}{|c|c|c|c|}
\hline $\begin{array}{c}\text { Areas of } \\
\text { educational goal }\end{array}$ & $\begin{array}{c}\text { Nature of } \\
\text { educational action }\end{array}$ & Teaching-Studying stage & Education evaluation body \\
\cline { 2 - 3 } & &
\end{tabular}

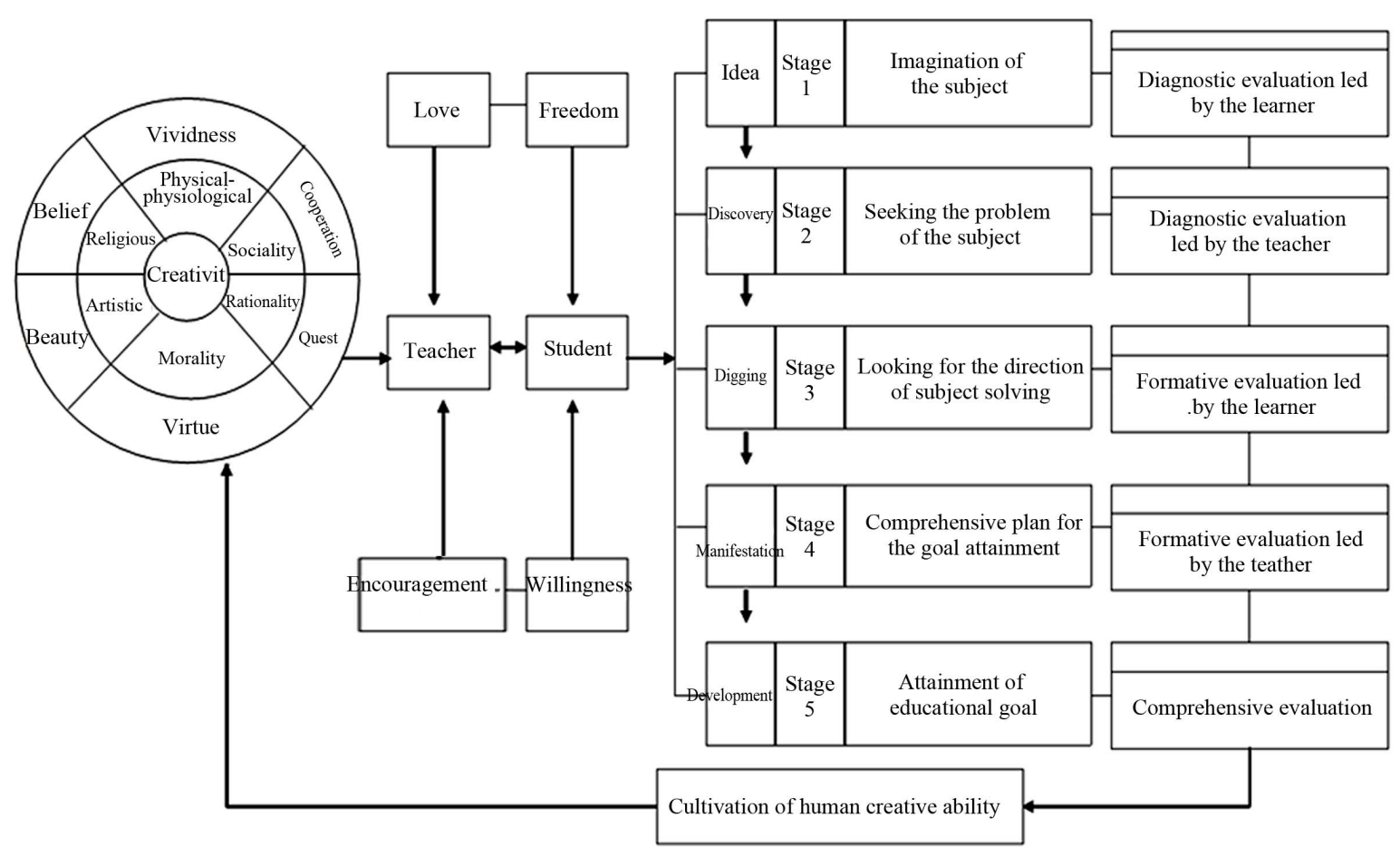

Figure 1.

The model of creative education teaching. 
value of character meaningful in creative education, even if it may achieve educational outcome in current functional education system. The five stages of teaching in creative education is he theory that presents the two aspects perfectly. The ideal type of thinking to create value is built in the five stages of teaching, based on the concept of freedom and willingness. The ideal type of thinking for building such value is to suggest the ideal type of teaching-studying such as idea, discovery, digging, manifestation, and development. In other words, creative education is to build the ideal type of thinking for value creation in advance and then present the corresponding teaching-studying. The ideal type of thinking for value creation is actual measure of education to realize the ideal type of teaching-studying. The ideal type of thinking for value creation in the five-stage teaching of creative education is meaningful as it is optimal method to realize the ideal type of thinking for value creation.

Then, what is the system to connect the type of thinking for value creation and that of teaching-studying, in creative education? Freedom and willingness as the type of thinking for value creation can be the notional classification to understand thinking reasonably. Freedom and willingness, that is, is the process of thinking that must be assumed to mention "Learner's thought has come.”, and from the viewpoint, freedom and willingness is the analysis unit of concept to grasp ideal thinking process. In other words, freedom and willingness are not the concept to provide educational measure in actual level but the concept to explain thinking in theoretical level. On the other hand, ideadiscovery-digging-manifestation-development is the concept for actual educational measure. It is not the concept from logical analysis of thinking but the concept to present the principle of method to be taken gradually so that thinking can be made rightly. The order of the five stages corresponds to the order of thought formation. To build the thought for value creation, the five stages need to be experiences notionally but in time gradually.

Idea-discovery-digging-manifestation-development is distinguished notionally and it is the concept to be classified stage by stagy in studying, while freedom and willingness are classified notionally only and it is connected concept from the aspects of subject and object.

The five-stage teaching of creative education, ultimately, is to build the system of teaching method for people's creating useful value through the change and cultivation of human ability by changing logical order to time series for thinking and then applying it to education.

\section{Conclusion}

The five-stage teaching of creative education is one of the teaching methods set up as educational methodology for the education purpose of human creativity cultivation. Creativity is understood as universal and holistic aspect of human in creative education, and the spheres of creativity can be classified into physical-physiological sphere, social sphere, rational sphere, moral sphere, artistic sphere, and religious sphere in human life and the properties of value ability in each sphere are presented. Vividness in physical-physiological sphere, cooperation in social sphere, quest in rational sphere, virtue in moral sphere, beauty in artistic sphere, and belief in religious sphere are defined as the properties of value ability and presented the educational purpose. Such spheres of creativity distinguish universal human life and the cultivation of creativity are established as the educational purpose. Teaching method in creative education consists of the five stages of teaching as integrated teaching-studying to cultivate the properties of value ability in each sphere of creativity, which is the stage of idea-discovery-digging-manifestation-development to encourage learner's freedom and willingness with teacher's love and guide.

Learner is the subject in the study course in the five-stage teaching and it is the teaching-studying theory to cultivate value ability through the learner's thinking and experience, connecting the ideal type of thinking for value creation to the ideal type of teaching-studying. Freedom and willingness as the ideal type of thinking for value creation are explained in theoretical level and the actual measure for education is tried in the teaching theory by the five-stage teaching of idea-discovery-diggingmanifestation-development as the ideal type of teaching-studying. In other words, creative education is to build the ideal type of thinking for value creation in advance and then present the corresponding teaching-studying. The five-stage of teaching in creative education is to build theoretical system of education to allow students to make creative value by themselves through the cultivation of human ability, changing logical order to time series in thinking and then applying it to education.

The five-stage of teaching in creative education is the formulization of thinking for value education for applying it to studying. It is theoretical composition of the stages to develop thinking for value creation through the experiences of the activity spheres, placing the study course to the learners. The five-stage of teaching can present the educational course as creative ability cultivation as well as the teaching for realization of educational self.

\section{REFERENCES}

Kim, J. A. (2008). A study on the development of teaching-studying model for creativity education, doctorial dissertation. Ph.D. Thesis, Iksan: Wonkwang University.

Kim, Y. C. (2007). Theory and development of creative ability. Paju: Education \& Science Press.

Yu, S. H. (1996). Creativity is made, translation. Seoul: Baeksinseodang Press.

Lee, D. H. (1993). Understanding of educational experience. Seoul: Education \& Science Press.

Lee, Y. G. (1999). Educational philosophical approach to creativity. Collection of treatises of creative education (Vol. 3), Society for Creative Education.

Lee, Y. G. (2000). Educational understanding of the nature of creativity. Collection of treatises of creative education (Vol. 4), Society for Creative Education.

Lee, Y. G. (2001). Creativity and educational self. Collection of treatises of creative education (Vol. 5), Society for Creative Education.

Lee, Y. G. (2005). Philosophy of education by Lee Jong-Rok-Thought and practice of creative education. Publishing Committee in Celebration of the $60^{\text {th }}$ Anniversary of Creative Education.

Lee, Y. G. (2011). Theory and practice of teaching method in creative education. Paju: Education \& Science Press.

Lee, Y. G. (2011). Theory and practice of learning for creative education. Paju: Education \& Science Press.

Lee, Y. G. (2011). Theory and practice of teaching-studying for creative education. Paju: Education \& Science Press.

Lee, Y. G. (2012). Formation and establishment of creative education in Korean modern education history. Collection of treatises of creative education (Vol. 14), Society for Creative Education.

Lee, J. R. (1974). Creative self and education. Academic Seminar, Iksan: Wonkwang University

Lee, J. R. (1987). Teaching-Studying for cultivating creativity, Collec- 
tion of dissertations (No. 1). Iksan: Graduate School at Wonkwang University.

Lee, J. R. (1997). Creative thinking and meditation. Collection of treatises of creative education (No. 1), Society for Creative Education.

Lee, J. R. (2001). Theory and method for creative education. Paju: Education \& Science Press.
Lee, J. R. (2001). Fundamental recognition of creativity. Seoul: Education \& Science Press.

Lee, J. R. (2003). Education philosophy. Seoul: Education \& Science Press.

Lee, J. R. (2005). Cultivation of creative ability and education. Seoul: Education \& Science Press. 